\title{
Analysis of calibrated seafloor backscatter for habitat classification methodology and case study of 158 spots in the Bay of Biscay and Celtic Sea
}

\author{
Fezzani Ridha ${ }^{1,{ }^{*}, \text { Berger Laurent }}{ }^{1}$ \\ ${ }^{1}$ IFREMER, Underwater Acoust Lab IMN NSE ASTI, Plouzane, France. \\ * Corresponding author : Ridha Fezzani, email address : Ridha.Fezzani@ifremer.fr \\ Laurent.Berger@ifremer.fr
}

\begin{abstract}
:
An automated signal-based method was developed in order to analyse the seafloor backscatter data logged by calibrated multibeam echosounder. The processing consists first in the clustering of each survey sub-area into a small number of homogeneous sediment types, based on the backscatter average level at one or several incidence angles. Second, it uses their local average angular response to extract discriminant descriptors, obtained by fitting the field data to the Generic Seafloor Acoustic Backscatter parametric model. Third, the descriptors are used for seafloor type classification. The method was tested on the multi-year data recorded by a calibrated $90-\mathrm{kHz}$ Simrad ME70 multibeam sonar operated in the Bay of Biscay, France and Celtic Sea, Ireland. It was applied for seafloor-type classification into 12 classes, to a dataset of 158 spots surveyed for demersal and benthic fauna study and monitoring. Qualitative analyses and classified clusters using extracted parameters show a good discriminatory potential, indicating the robustness of this approach.
\end{abstract}

Keywords : Multibeam, Reflectivity, Backscatter angular response, Segmentation 


\section{Introduction}

Since many benthic organisms depend on specific habitats to complete their life cycle, the knowledge of the spatial extent of different seafloor habitat is fundamental to our understanding of fish populations and movements, and for the management of fisheries in the context of sustainable exploitation. Among today's sonar systems, multibeam echosounder systems (MBES) are the most advanced cost-effective acoustic tools usable for generating benthic habitat maps (Brown et al., 2011). In addition to their fundamental bathymetric functionality, MBES can measure the backscattered intensity of the echo signals returned from the seabed. On-going developments in data processing and absolute calibration of MBES are dramatically improving the quality and potential of these backscatter data (Lurton and Lamarche, 2015). Moreover, multibeam sonars can provide the backscatter variation over a wide range of incidence angles, which is a powerful proxy for the intrinsic properties of the seafloor (Fonseca et al., 2009) and can be used to classify and characterize the seabed type, along with the wide coverage capability which is essential for rapid assessment of habitats over large areas. However, the use of MBES for generating habitat maps is inevitably confronted with some difficulties in analyzing and processing its measurements. Despite efforts in the most recent MBES systems to deliver reliable 
levels of reflectivity, their built-in compensations still suffer from a lack of calibration and control capability for absolute backscatter measurement. This lack of precision raises problems for quantitative analysis and comparison with physical models. A thorough background of various possible solutions for intensity calibration of multibeam sounders can be found in Lurton and Lamarche (2015). Most absolute calibration approaches depend on the availability of additional measurement facilities in tank or at sea, making them hardly practical for most users, especially since it is ideally necessary to calibrate the sounder regularly to monitor the drift of its characteristics with time. Moreover, due to the large volumes of data collected using today's MBES, the need has arisen for developing automated computational methods that are robust, accurate and replicable. Three types of MBES datasets are commonly used as features or sources of derivative features for the seafloor classification process: bathymetry, backscatter mosaic and backscatter angular response (Hasan et al., 2014). Processing MBES backcatter data is a more complicated procedure than bathymetry data analysis. There are basically two different automated segmentation methods for backscatter data: image-based segmentation relies on a textural analysis of the grey-level mosaic image; and signal-based segmentation analyses the angular dependence of backscatter intensity. The first one relies on recognizing the small-scale spatial features in the sonar image and their variation due to geographical changes in seafloor-type only, since the backscatter intensity data are usually normalized for their angular dependence prior to mosaicking (e.g, Brown and Blondel (2009); McGonigle et al. (2011); Edwards et al. (2003)). In this approach, final classes need in situ ground-truthing to be validated using sediment samples or underwater video recording. In contrast, the second method implies a reliable measurement of the absolute backscatter level (Hughes Clarke et al., 1997). The variation of the mean backscatter strength with the incidence angle, practically obtained by averaging several neighboring samples or consecutive pings, is an intrinsic property of the seafloor (Fonseca et al., 2009) and therefore potentially allows seafloor classification and characterization (Lurton, 2010), despite its coarser resolution compared to image mosaic processing. Many previous studies have proposed different features either extracted from the backscatter angular response only or combined with other descriptors from image mosaic and bathymetry for habitat mapping (Pirtle et al., 2015; Hasan et al., 2014; Lamarche et al., 2011; Brown and Blondel, 2009; Fonseca et al., 2009; Hughes Clarke et al., 1997). The present study explores the potentiality of calibrated measurements of absolute backscatter angular response for analysis and automatic classification of benthic habitats, applied to data collected with a calibrated Simrad ME70 MBES, during multi-annual fishery resource surveys in the Bay of Biscay, France and Celtic Sea, Ireland, both in the east Atlantic Ocean.

\section{Materials and Methods}

\subsection{MBES dataset}

\subsubsection{Acoustic data acquisition: overview}

The acoustic data were collected, by Ifremer as part of yearly sea cruises run for evaluation of fisheries resources in western Europe (EVHOE program) in the Bay of Biscay and Celtic Sea. EVHOE provides quantitative and qualitative data on fish populations and aims to map the spatial distributions of species and to study the inter-annual variability of benthic and demersal fauna. It covers the vast majority of habitats visited by 
fishing vessels in the Bay of Biscay and the Celtic Sea in water depths ranging from 30 to $400 \mathrm{~m}$. On each area, trawl nets are operated in precisely predetermined locations. From 2008 to 2016, 158 areas were surveyed by the fisheries research vessel Thalassa (see Figure 1). Some of these areas were surveyed more than once, so a total of 190 surveys was achieved during this period. Datasets were collected using a hull-mounted Simrad ME70 multibeam echosounder MBES, which is a scientific sensor developed for quantitative estimates of backscatter in the water column for pelagic fish stock assessment and research in marine organisms ecology (Trenkel et al., 2008). In 2008, a bathymetric module was added to the system in order to provide IHO Order-1 (IHO, 2008) bathymetry data for seafloor-mapping purposes (Cutter et al., 2010). The great advantage of ME70 over other MBES for collecting absolute backscatter measurements is its operational capability for at-sea calibration using a reference sphere target (Ona et al., 2009). This operation was conducted before each survey and its expected accuracy is fully described in an ICES report (ICES, 2016). In our study, bathymetry and backscatter data were acquired with the ME70 operated with its bathymetry module. The average accuracy of the calibration expressed as the RMS (root mean square) of the measured TS (target strength) of the reference sphere, for all surveys presented here is estimated about $0.4 \mathrm{~dB}$ for all beams of the bathymetric mode. The ME70 data acquisition in bathymetric mode is interfaced with the Kongsberg Seafloor Information System (SIS) software suite for bathymetry and backscatter production. The ME70 bathymetric module operates under a single configuration including : one $90-\mathrm{kHz}$ transmission sector, with a total angular aperture of $120^{\circ} ; 3^{\circ}$ central beam width; 81 equidistant or equiangle beams, each with two (384 or $768 \mu s)$ pulse-duration values, providing up to 200 soundings per swath. The data are compensated for vessel motion (heave, pitch, roll, and yaw) and corrected for water-column sound speed variations. All MBES surveys followed the same protocol in order to ensure the recovery of a central bottom-trawl line with an extension of 500 to $1000 \mathrm{~m}$ at both ends of the line (Figure 2). Area dimensions and parallel survey lines spacing were defined according to minimum depth of the area: parallel lines were spaced 0.75 times the swath width to ensure sufficient overlap between lines. In each survey area a cross-line was run for bathymetric data quality control, and proved to be very valuable for backscatter analysis.

\subsection{Backscatter data preprocessing}

Bathymetric data (collected using the Kongsberg SIS software Suite) are fully corrected for ship's motion, navigation and sound velocity (SIS, 2010). Application of corrected tides and bathymetric data cleaning are processed using the Ifremer seafloor mapping software CARAIBES ${ }^{\complement}$ (v5) and tide reference data provided by SHOM (Hydrographic Service of the French Navy). A second step consists in using cleaned bathymetry with validity flags to create a gridded bathymetry. Backscatter data were processed using the SonarScope ${ }^{\circledR}$ (v2017) software of Ifremer, and cleaned using the same flags validity (Augustin and Lurton, 2005). In SonarScope ${ }^{\circledR}$ the backscatter data is imported directly from the datagrams and reduced following these corrections steps:

- Correction of transmission losses associated with absorption and oblique range.

- Application of calibration gains (adjustments estimated from a reference sphere calibration).

- Correction for the instantaneous insonified area, as a function of the true incident angle using the local 3D slope derived from the gridded bathymetry, beam width and pulse duration. 
The output of this reduction process is considered as our best estimate of the absolute backscatter angular response for the survey area.

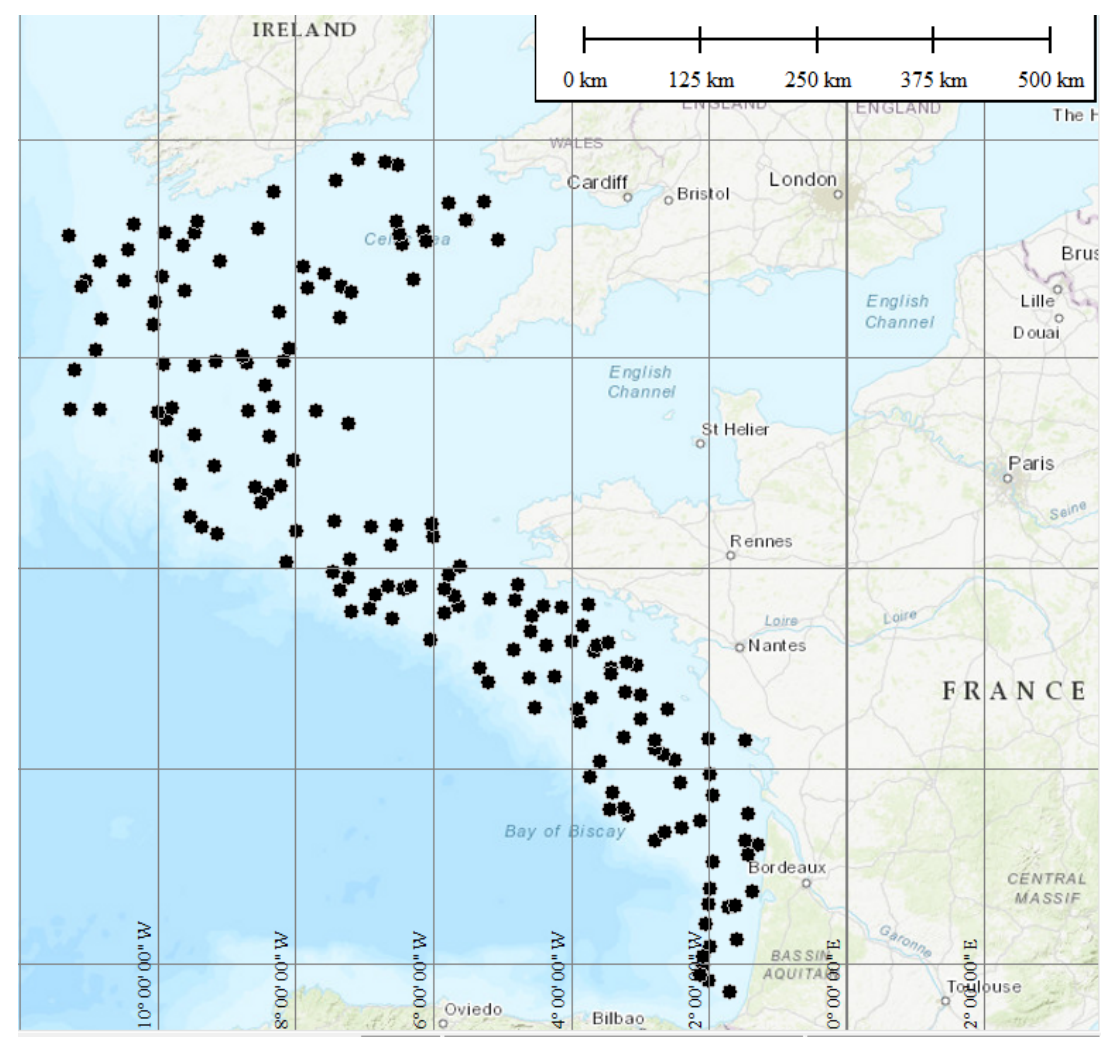

Figure 1: Locations of the surveyed areas between 2008 and 2016 during EVHOE sea cruises (black stars). Some areas were surveyed more than once.

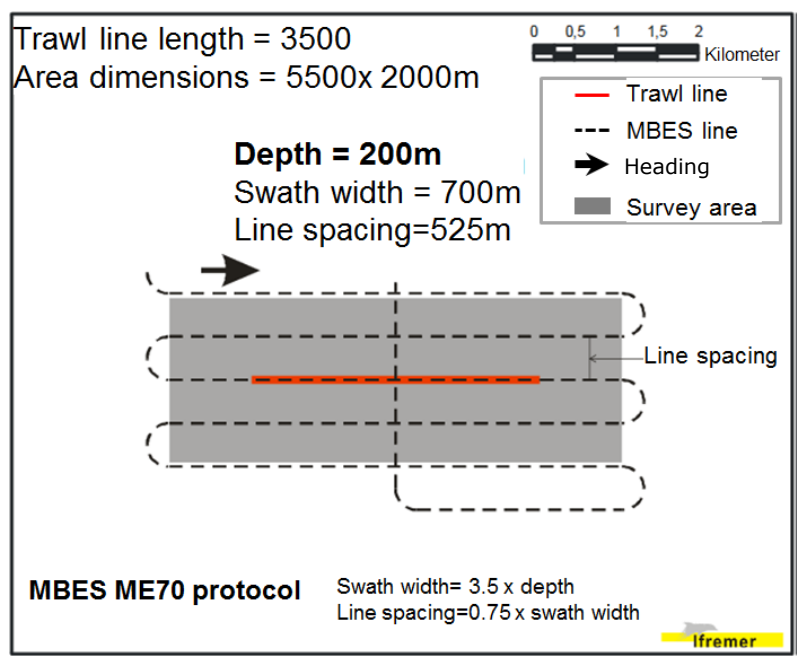

Figure 2: ME70 protocol for the EVHOE campaigns: area dimensions, survey and trawling line geometry; the line spacing depends on seafloor depth. 


\subsection{Angular Response modeling and metrics extraction}

Following the application of the corrections described above to the observed backscatter, the next step is the extraction of descriptors for each survey area. For this purpose, our method is divided into two steps: clustering each area into homogeneous sediment types, formation of a representative average angular response for each seafloor type and extraction of metrics for seabed characterization.

\subsubsection{Clustering}

A range of methods can be used for the seabed segmentation into acoustically homogeneous areas using the acoustic backscatter angular responses:

- Ping-to-ping backscatter levels at a specific angular beam (Simons and Snellen, 2009). Generally, at oblique angles the backscatter strength is more stable than at nadir; as recommended in Lamarche et al. (2011) we used the $45^{\circ}$ angle for backscatter analysis.

- Feature extraction associated or not with inverse modelling of the acoustic backscatter angular response (Hughes Clarke, 1994; Fonseca and Mayer, 2007).This technique may require calibrated backscatter data.

- Statistical clustering of the multibeam sonar backscatter curves in their entirety (Hamilton and Parnum, 2011). This method treats the entire backscatter curve as a single geometric entity and tends to cluster curves according to their shape uniformity. This technique does not need any compensation step.

Since all these methods use the angular dependency of the backscatter response, they provide only a single cluster per swath, or per half-swath if both sides (port and starboard) are used separately. However, the large area of seabed covered by a full swath might not present a homogenous seabed type and smaller scale spatial trends may exist within a swath or half-swath width. In such cases, image processing techniques are often used to obtain additional information at finer scales.

In our study, the backscatter angular curve is used for the seabed segmentation into acoustically homogeneous areas at sub-swath scales. Figure 3 shows a flow chart of our approach applied to a dataset recorded in the Bay of Biscay. The mosaic image (Figure 3a) is used only for preliminary data display and visual control of data quality (outliers, influence of weather conditions,...) and number of homogenous area. The segmentation process is applied to the backscatter values obtained from stacking of all sonar pings of the area (ping vs beam representation given in Figure 3b). The inherent ping-to-ping backscatter variability is first reduced using an averaging sliding window of $3 * 3$ values corresponding in average to $15 \mathrm{~m}$ along-track and $7 \mathrm{~m}$ across-track. A second step consists in clustering backscatter values of all ping stacks at each angle beam (200 beams) independently to two classes using the Kmeans algorithm (Hartigan and Wong, 1979): homogeneous clusters are grouped by sorting the segmentation result from each beam angle. This remains possible for all incidence angles because coarse sediment backscatter is higher than for smooth sediment at all angles excepted in some cases at near-nadir angles (Jackson et al., 1986). Figure 3c shows the good result of the data segmentation of Figure 3b except as expected at nadir: this is due to the backscatter variability at specular angles and this is indeed a challenge for image processing techniques using specular filtering to avoid classification artifacts. In our 
case, the segmentation results in specular area can be improved by using image morphological operations on the segmentation results of Figure 3d. By choosing the size and shape of the neighborhood structuring element we can connect homogeneous classes at specular area and improve the segmentation result. In Figure 3d, we have applied a horizontal linear "opening" element in the specular area followed by a "closing" element, the size of the element is defined as the specular width, estimated by applying the GSAB model (see subsection 2.3.2) to the mean curve of the whole area (1.5 times parameter B). Opening and closing operators are applied using Matlab ${ }^{\circledR}$ software (imopen and imclose functions). The result shows a significant improvement of the segmentation result in near-nadir area. A mosaic of the resulting segmentation is presented in Figure 3e. One can notice the good segmentation result compared to the original backscatter mosaic (Figure 3a), with a quality comparable to that of image processing techniques. Figure $3 \mathrm{f}$ shows the angular backscatter response of each class obtained by averaging all pings from each class. At this stage, we get the absolute backscatter of homogeneous areas at fine scale, which will be used for final classification after features extraction.

All segmentation steps are applied systematically to each survey area to extract two angular backscatter curves per area. The decision of segmenting into two classes was made when analysing backscatter mosaic when processing manually the bathymetry of each area.

\subsubsection{Descriptor extraction}

For parameters extraction, we used the Generic Seafloor Acoustic Backscatter (GSAB) model (Lamarche et al., 2011). The GSAB is not a physical backscattering model, but rather a practical tool for fitting field data on seafloor properties. It was initially designed to be used in the compensation process of directivity patterns for MBES data (Hellequin et al., 2003). It features four to six parameters ( $A$ to $F$, see below), which make it possible to fit the specific behaviors of the backscatter evolution as a function of the incidence $\theta$ angle.

The GSAB model is broken down into:

- a normal distribution $A \exp \left(-\theta^{2} / 2 B^{2}\right)$ of the specular signal;

- a cosine component, namely: a the Lambert-like law $C \cos ^{D}(\theta)$ describing best the grazing-angle regime;

- a secondary normal law $E \exp \left(-\theta^{2} / 2 F^{2}\right)$ ensuring the transition between the two previous modes and making it possible to take account of a slower angular growth for certain types of seabed.

The following mathematical expression, expressed in $\mathrm{dB}$, summarizes the different components of the model:

$$
\begin{array}{r}
B S(\theta)=10 \log \left[A \exp \left(-\theta^{2} / 2 B^{2}\right)+C \cos ^{D}(\theta)\right. \\
\left.+E \exp \left(-\theta^{2} / 2 F^{2}\right)\right]
\end{array}
$$

The parameters $A$ to $F$ are not in direct relationship with geological and seafloor properties in the way used classically in other models (e.g., Jackson et al. (1986)). However, they can provide a discriminating description of the acoustic backscatter of the sediment with a physically consistent meaning (Lamarche et al., 2011). An example of the GSAB model fitting on data using a nonlinear least square algorithm is presented in Figure 4. In addition to the six GSAB parameters, two other descriptors were extracted from the backscatter angular response: (1) the specular-to-oblique level difference $\left(B S_{n}-B S_{o}\right)$ given by $B s\left(\theta=0^{\circ}\right)-B s\left(\theta=45^{\circ}\right)$ and $(2)$ 


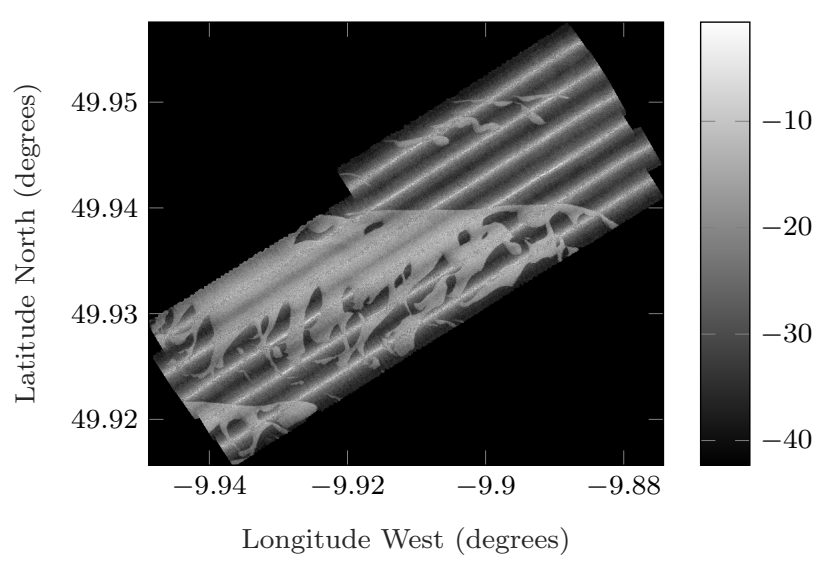

(a) 5-m resolution mosaic of the area

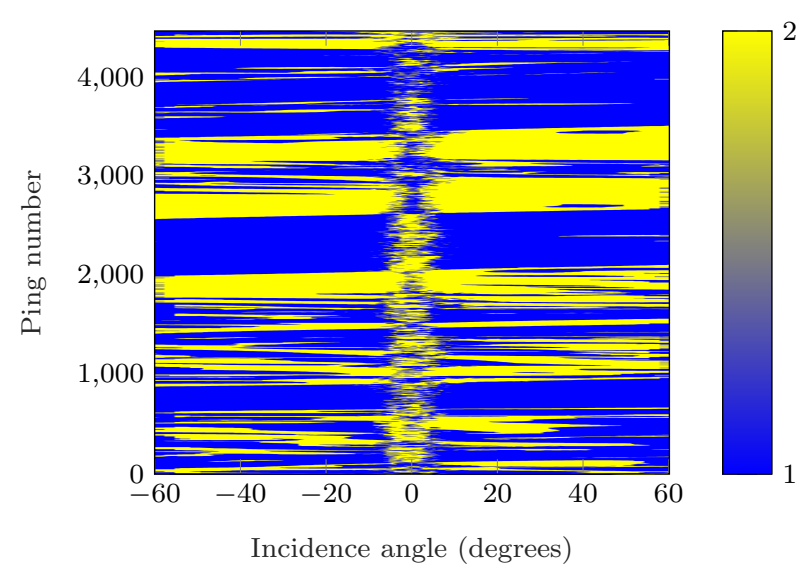

(c) First result of segmentation into 2 classes

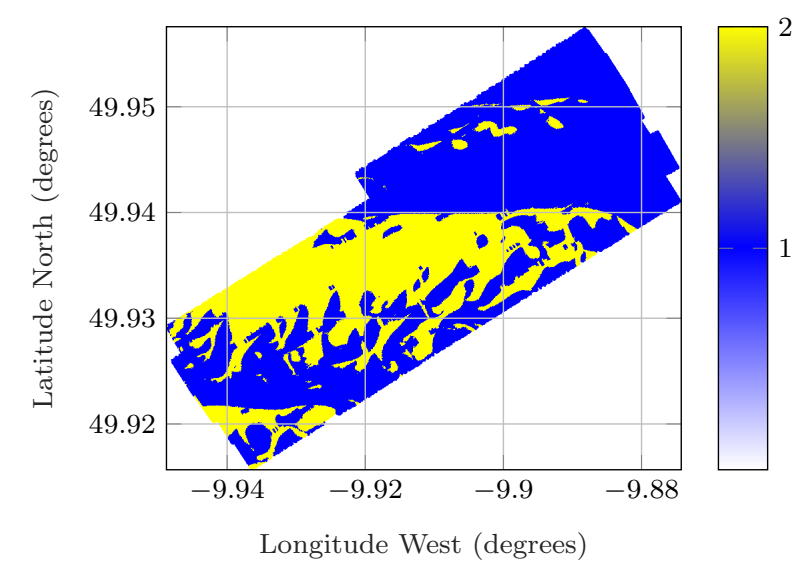

(e) 5-m resolution mosaic of the segmentation result

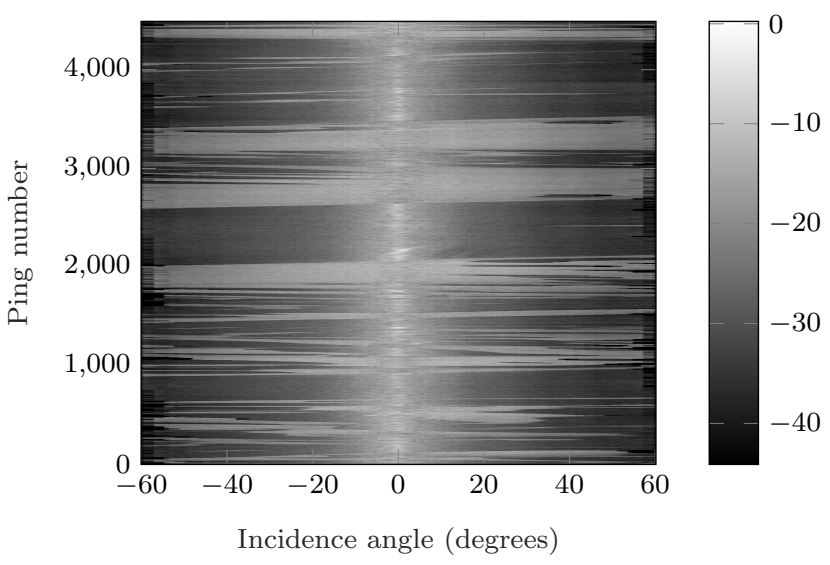

(b) Ping Beam backscatter geometry of the surveyed area in $\mathrm{dB}$

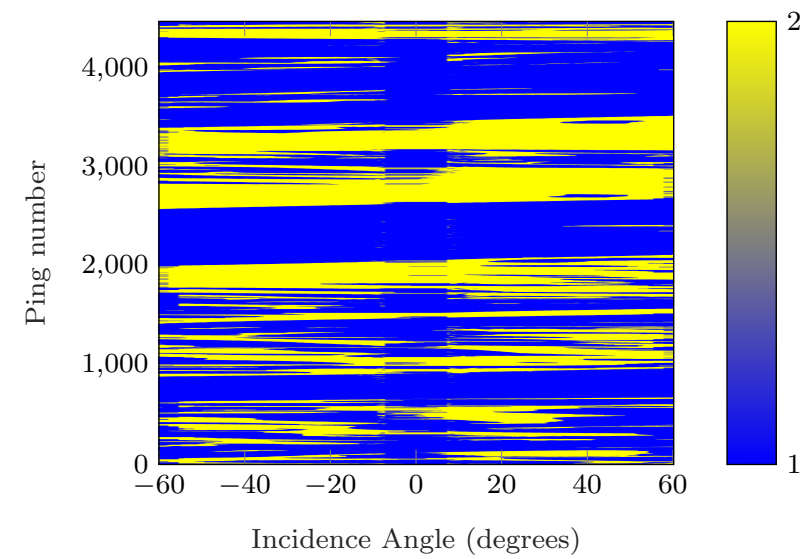

(d) Result of segmentation into 2 classes after application of morphological operations near nadir

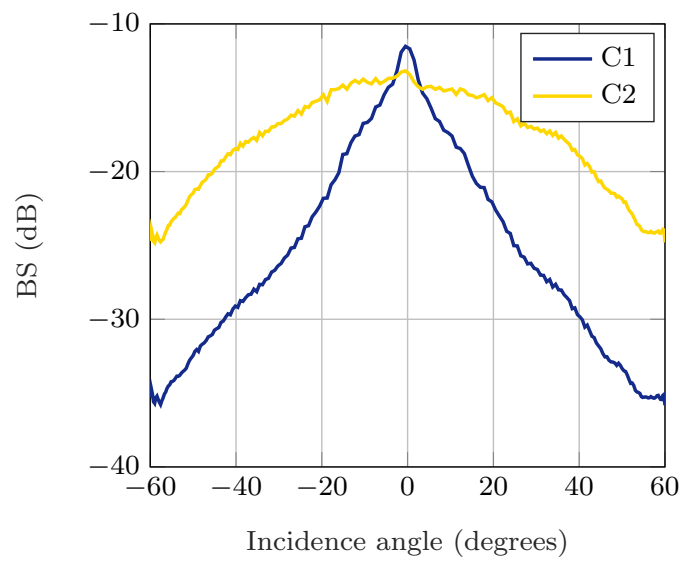

(f) Backscatter angular response obtained by averaging per angle bin the pings associated to each class

Figure 3: Example of backscatter clustering process

the average dispersion of the angular response calculated as the absolute average of the difference between 5 and 95 percentiles. These parameters were found to be useful in the classification process (see Section 3). 


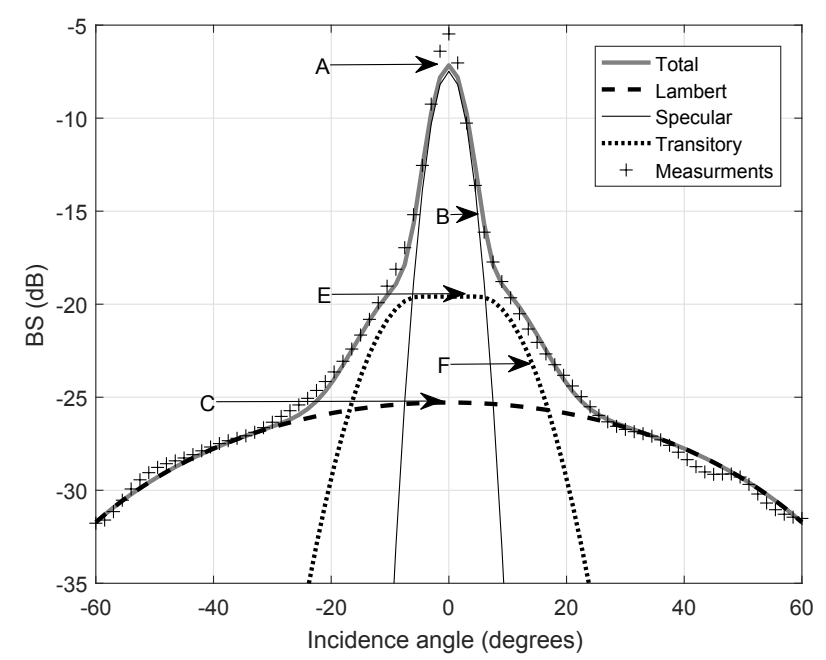

Figure 4: Example of fitting GSAB model to data.

\section{Results and discussion}

\subsection{Qualitative analysis}

There are very few ground-truth data available for seabed characterization from the EVHOE campaigns to interpret collected data or to evaluate our results on any of the surveyed areas as the EVHOE objective was to extract descriptors for demersal and benthic organisms habitat monitoring rather than acoustically homogeneous areas classification and seabed characterization.

The first observation over all extracted backscatter angular responses is the large variability of levels and shapes of curves despite their preliminary averaging at the scale of homogeneous areas. Statistics of extracted descriptors used in data analysis are listed in Table 1. Over the 158 areas, the dynamics of the specular and Lambert levels ( $A$ and $C$ in equation (1)) reach respectively 38 and $20 \mathrm{~dB}$. These ranges indicate important variations in seafloor impedance and roughness or sediment volume scattering. These variations confirm the relevance of using an empirical model with a few parameters instead of theoretical modelling to describe general trends and identify local variations.

Among all the processed areas, a number of typical characteristics can be identified, that will be described in the following paragraphs.

\section{Backscatter azimuth dependence.}

The southern and eastern parts of the Bay of Biscay are covered by sand-type sediment and show a well-marked dynamic character characterized by the presence of strong tidal currents. In these areas, a clear dependence of the backscattering angular responses with survey directions can be observed. This azimuth dependence is caused by small-scale sand ripples and their orientation. This effect is analysed in Lurton et al. (2017) for similar sandy areas.

Figure 5 presents angular responses of two close areas in the southern Bay of Biscay surveyed on the same week in 2010 at two different headings $\left(0^{\circ} / 180^{\circ}\right.$ and $\left.110^{\circ} / 290^{\circ}\right)$. The angular response of several averaged parallel 


\begin{tabular}{|c|c|c|c|c|c|c|c|l|}
\hline & $A(\mathrm{~dB})$ & $B\left(^{\circ}\right)$ & $C(\mathrm{~dB})$ & $D\left(^{\circ}\right)$ & $E(\mathrm{~dB})$ & $F\left(^{\circ}\right)$ & $B S_{n}-B S_{o}(\mathrm{~dB})$ & $\begin{array}{l}\text { Inter-quantile } \\
\text { width }[5-95](\mathrm{dB})\end{array}$ \\
\hline Mean & -12.58 & 9.77 & -21.25 & 3.58 & -18.40 & 16.06 & 16.07 & 8.10 \\
\hline Max & -0.10 & 20.0 & -9.59 & 5.99 & -3.71 & 20.0 & 27.38 & 13.86 \\
\hline Min & -38.04 & 0.60 & -29.77 & 0.25 & -29.87 & 0.95 & 4.69 & 5.84 \\
\hline Std & 4.96 & 4.95 & 3.67 & 1.06 & 3.49 & 3.69 & 4.13 & 1.56 \\
\hline
\end{tabular}

Table 1: Seafloor metrics statistics derived from the complete data collected with the ME70 MBES during EVHOE sea cruises. Parameters $A$ to $F$ refer to the GSAB model for angular reflectivity. $B S_{n}-B S_{o}$ is the specular to oblique contrast. The Interquantile width is the absolute average of the difference between 5 and 95 percentiles

lines and one cross-line for each area highlights the backscatter azimuth dependence. As the sediment type is the same on both areas, a similarity appears between the response of parallel lines of an area and of the cross-line of the other as the difference in survey heading for the two areas is close to $90^{\circ}$. Such an observation highlights the necessity of running cross-lines during MBES surveys not only for bathymetry quality control but also for detection of a possible roughness polarization.

Azimuth dependence appears generally over the incidence angle range $\pm 5^{\circ}$ to $\pm 35^{\circ}$. Beyond $40^{\circ}$ backscatter is independent of the azimuth angle. The maximum observed difference in the backscatter strength values reaches $8 \mathrm{~dB}$ at $30^{\circ}$. These results are in agreement with those related and interpreted in a previous study in the Bay of Brest (Lurton et al., 2017).

We did not observe a roughness polarization directly in the sonar data (DTM or mosaic), because ripples can occur on a scale comparable to or smaller than the MBES footprint. Using a geoacoustic model to estimate geological descriptors without account of this roughness polarization can therefor lead to erroneous results.

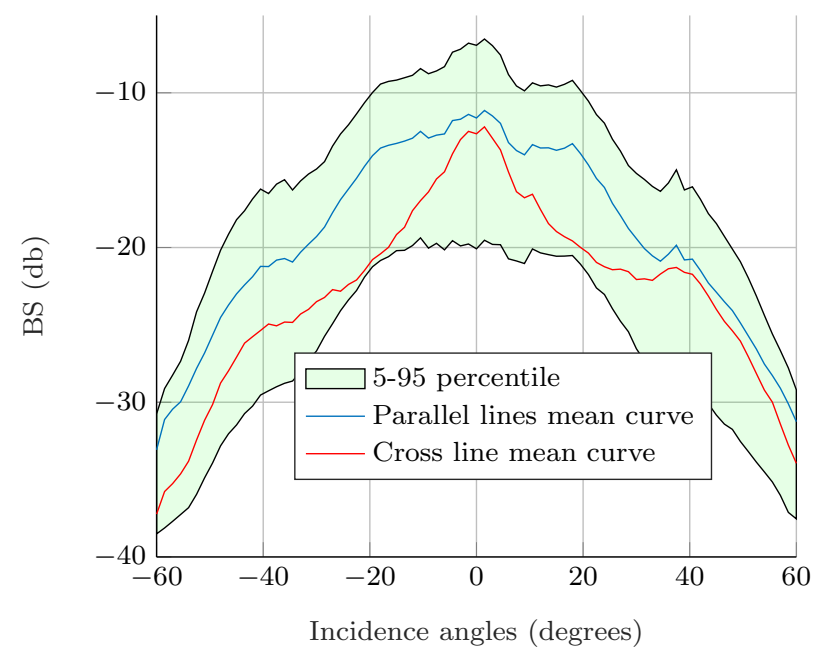

(a) Average angular response for Area 1.

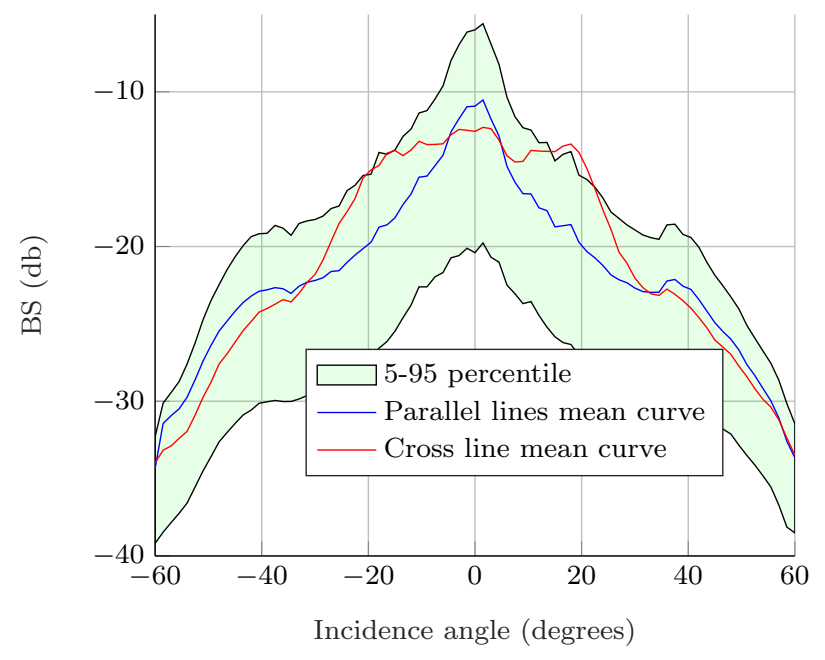

(b) Average angular response for Area 2.

Figure 5: Azimuth dependence of backscatter angular response of two closed areas $(10 \mathrm{~km})$ in the south of the Bay of Biscay. Area 1 is surveyed in the $0^{\circ} / 180^{\circ}$ direction. Area 2 is surveyed in the $110^{\circ} / 290^{\circ}$ direction. 


\section{Backscatter time dependence.}

The stability of the seafloor backscatter response over time is key information in habitat monitoring. Causes of seabed characteristics changes can be either natural (tides, currents, storms, etc.) or due to human activity (trawling, dredging, anchoring, etc.). Such changes may be difficult to observe by mosaic image analysis, especially in presence of roughness polarization where the angular information is normally neglected during backscatter standard processing and mosaicking. In Montereale-Gavazzi et al. (2017) the change detection using backscatter data is carried out by using both classified and unclassified (relative dB values) backscatter mosaics, as well as applying ensemble approaches.

Angular response analysis is a simple, robust and efficient way to control temporal stability of seafloor backscattering. Figure 6 shows the average backscatter of two areas. The first one (Figure 6a) is located in the south of the Bay of Biscay; it was surveyed twice (in 2010 and 2015) along the same survey line direction. The differences in angular response may reveal a change in sediment properties, but more likely a variation in the interface microroughness due to seasonal sand ripples because the two curves fit above $40^{\circ}$ incidence angle. It is paramount to account for this phenomena of sand ripple orientations when analyzing backscatter data for seafloor characterization. The second area (Figure 6b) in the Celtic sea was surveyed in 2011, 2013 and 2014 in two different directions. The angular responses show the good stability of sediment backscatter in this area. The similarity of the three curves measured over three years justifies the importance of the yearly backscatter calibration procedure applied to the ME 70 echosounder used for this study.

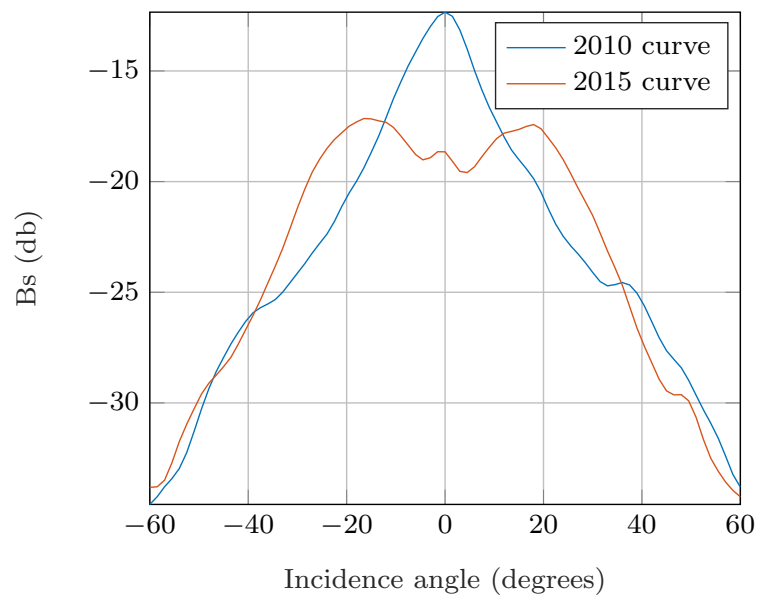

(a)

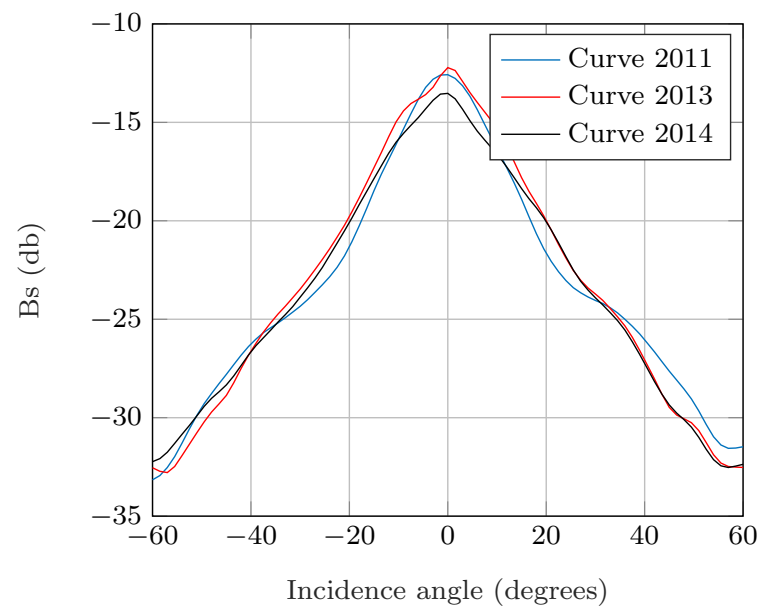

(b)

Figure 6: Temporal backscatter changes for two areas surveyed several times. (a) Backscatter angular response of area in the center of Celtic Sea surveyed 3 times with two different directions. (b) Backscatter angular response of area in the south of Bay of Biscay surveyed in 2010 and 2015 in the same direction. In (a), the angular response shows an azimuth dependance. Seafloor backscatter strength in Area (b) is unchangeable during the three years of survey(variation between years is less than 1 dB for all angles).

\subsection{Seafloor classification}

Despite the complex variability of the curves extracted from the 190 surveys and the lack of ground-truth elements, we propose now to cluster all these curves using the eight descriptors (see 2.3.2) extracted from the 
GSAB model and the backscatter statistics. The only data giving a priori information usable for comparison is an European seabed habitat map at large scale available at The European Marine Observation and Data Network (EMODnet) website (EMODnet, 2016). From the EVHOE surveys positioned on the EMODnet map, five sediment classes are identified: sandy mud, sand, muddy sand, mixed sediment, coarse sediment. Seabed substrate coverage is mapped at $1: 250,000$ scale near shore and $1: 1,000,000$ scale for the complete European waters. When analysing the angular backscatter curves extracted from all areas, it was decided to classify the whole region into more than five types because of the variability of curves in terms of shape and level. For classification, we applied a Gaussian Mixture Model algorithm (GMM) using the eight extracted descriptors to cluster curves. We tried first to identify automatically the number of viable clusters using statistical aids such as the Silhouette coefficient (Rousseeuw, 1987) and the Akaike Information Criterion (AIC) (Akaike, 1973). However, because of the large variability of the curves, these criterions always converged to the maximum allowed number of clusters. Thus, after some tests it was decided to cluster all curves to twelve acoustically homogeneous sediment types according to their shapes and levels. The clustering results are presented in Figure 7 . The regular progression of the clustered angular curves from $(a)$ to $(l)$ can be interpreted as ranging from fine sediment types to the coarsest ones. Indeed, cluster $(a)$ has the typical shape of a mud or fine sand sediment type with a strong specular peak, while cluster $(l)$ looks like coarse sediment or rock with a predominant Lambert-like shape. Clusters $(b)$ to $(k)$ act as transitions from sand to coarse sediment with the decreasing of the specular width and the widening of the Lambert-like law. As expected, the presence of azimuth dependence is inferred inside Class $(e)$ (Figure 7e) characterized by its specular regime spreading up to $30^{\circ}$. Cluster $(f)$ (Figure $\left.7 \mathrm{~d}\right)$ is also an azimuth-dependent case but with a specular width less than $15^{\circ}$ per side. Some curves of this cluster have an asymmetrical specular angles. An analysis of the causes of this phenomenon lead us to surmise that it originated from small asymmetry of seafloor ripples: a wrong compensation of ship's motion or calibration gain would have impacted the bathymetry quality and angular backscatter curves on other areas. All curves in cluster $(l)$ (Figure 7l) have a high Lambert level specific to coarse sediment. We notice that the highest backscatter values of this cluster (black, magenta and cyan curves) are not rocks (rock curves were identified from the bathymetry and backscatter mosaics are the red and blue lines). Such cases are difficult to interpret without ground-truthing. Despite the similarity of angular response shapes inside each cluster, the variations of backscatter level per angle bin are still high $(10 \mathrm{~dB})$ inside each class. This is likely due to the variability of sediment grain size inside each class and suggest that a finer classification (more than twelve class, allowing intermediate cases) could be of interest provided that ground-truth were available. With this method of unsupervised clustering, the shape similarity of backscatter curves appears to provide a sediment classification significantly finer than the one from the EMODnet map.

To analyse the spatial repartition of clusters, we mapped them as a simple triangulated irregular network. The positions (lat, long) are calculated as the mean position of each cluster of each survey area. The cluster number represents the third dimension for triangulation. The result is shown in Figure 8 as a map. Fine-soft (blue) and coarse-hard (red) clusters range between the lowest and highest cluster numbers of Figure 7 . The intermediate classes (green) represent sandy clusters. One can notice the spatial homogeneity of closed survey 
areas and the continuity across non surveyed areas. 
(a)

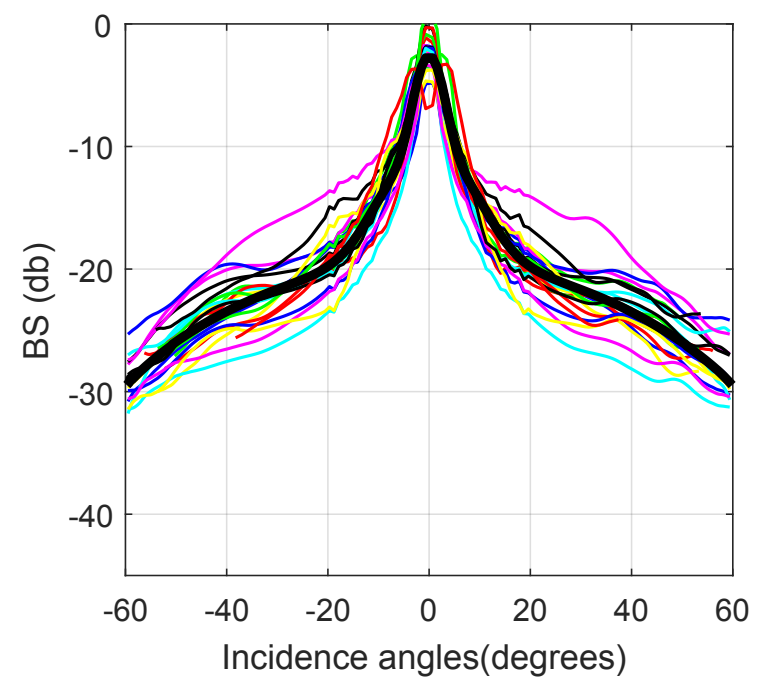

(c)

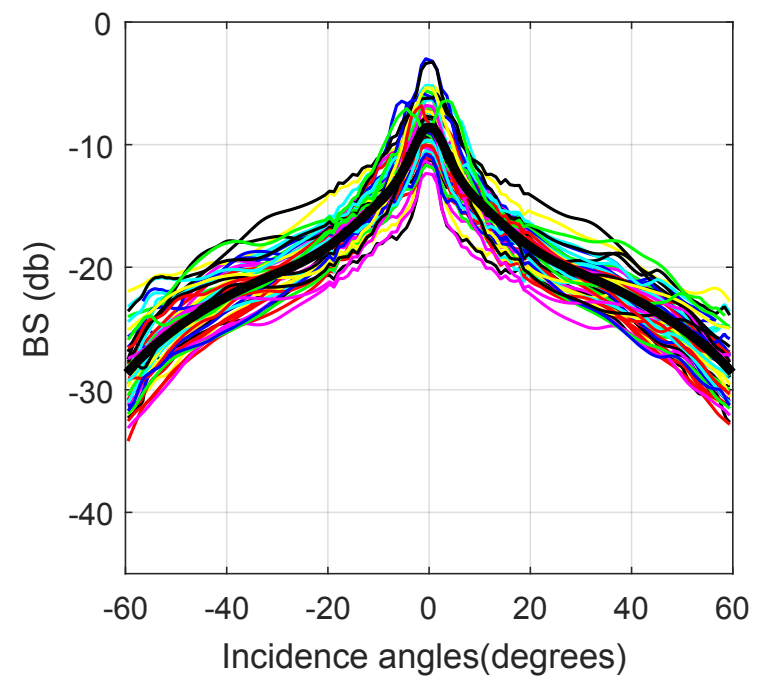

(e)

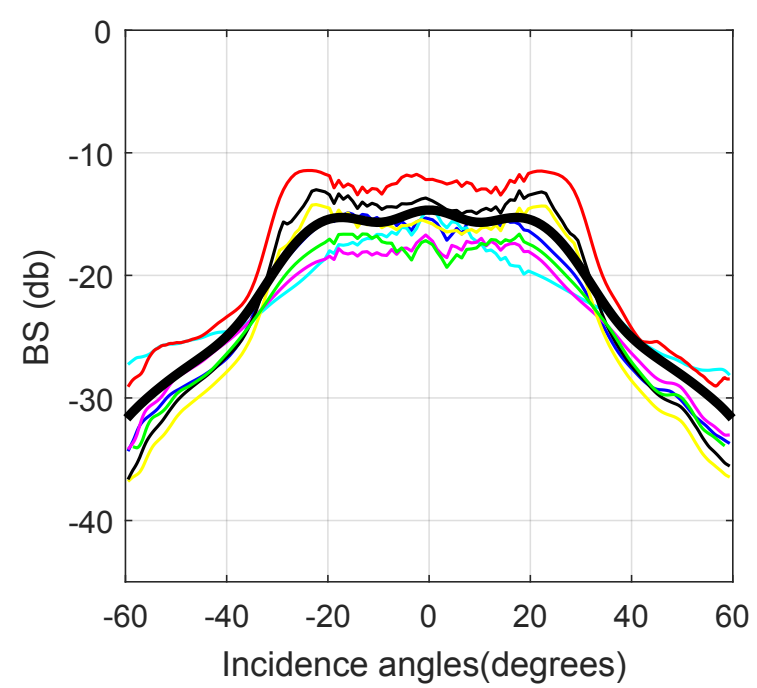

(b)

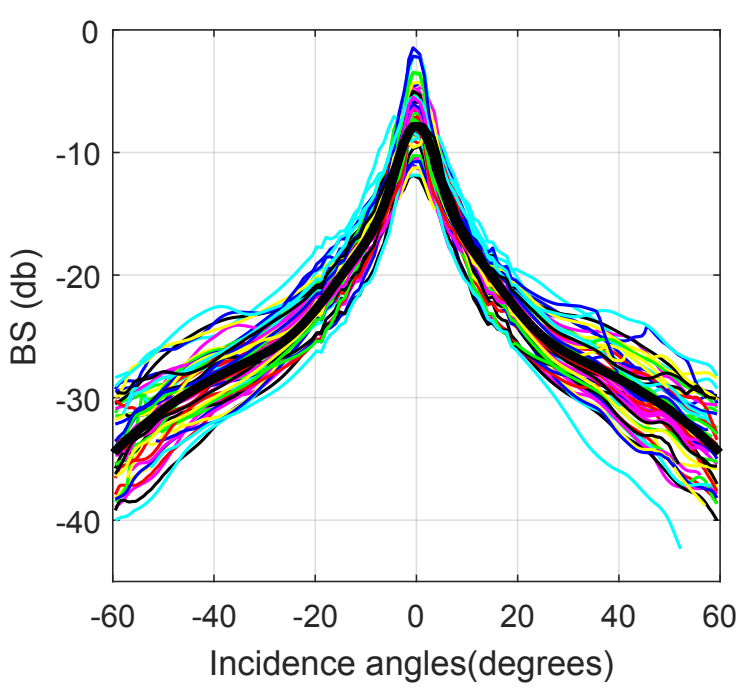

(d)

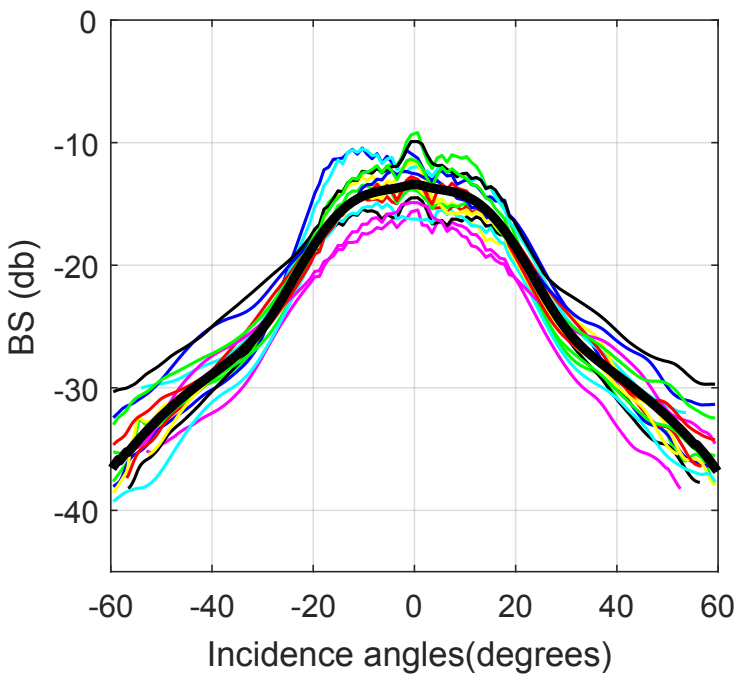

(f)

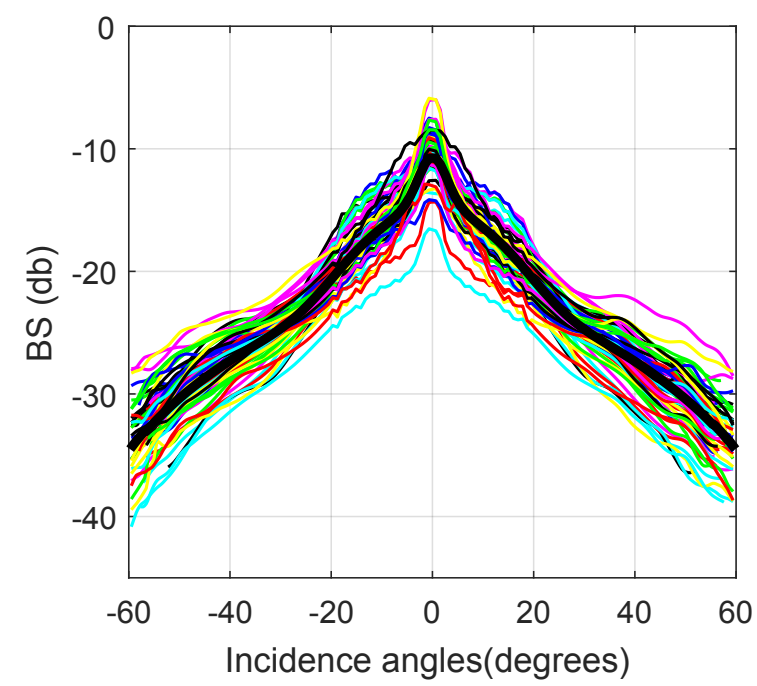


(g)

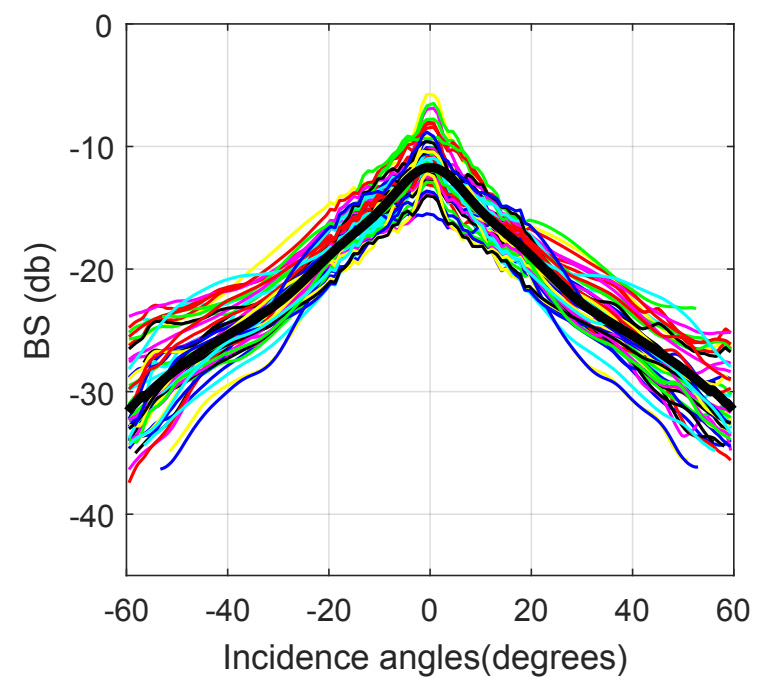

(i)

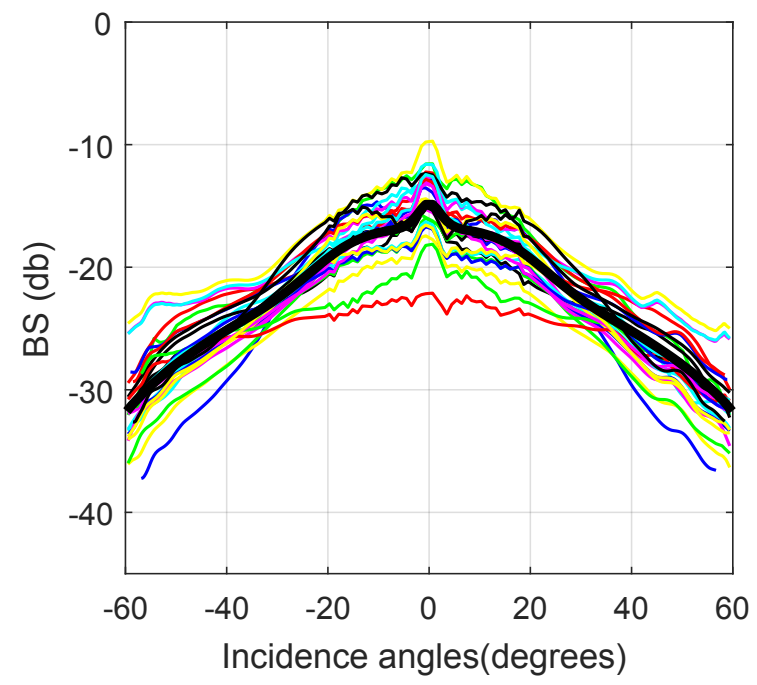

(k)

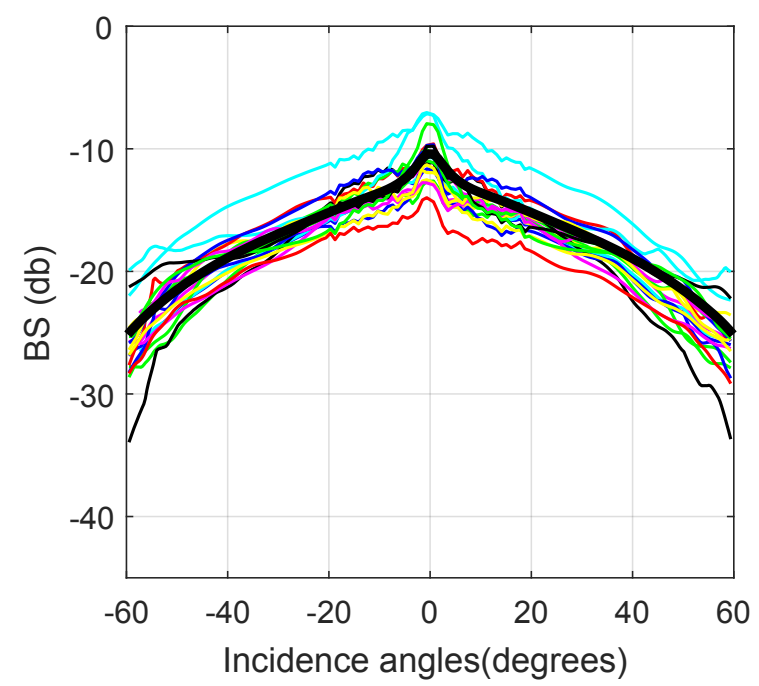

(h)

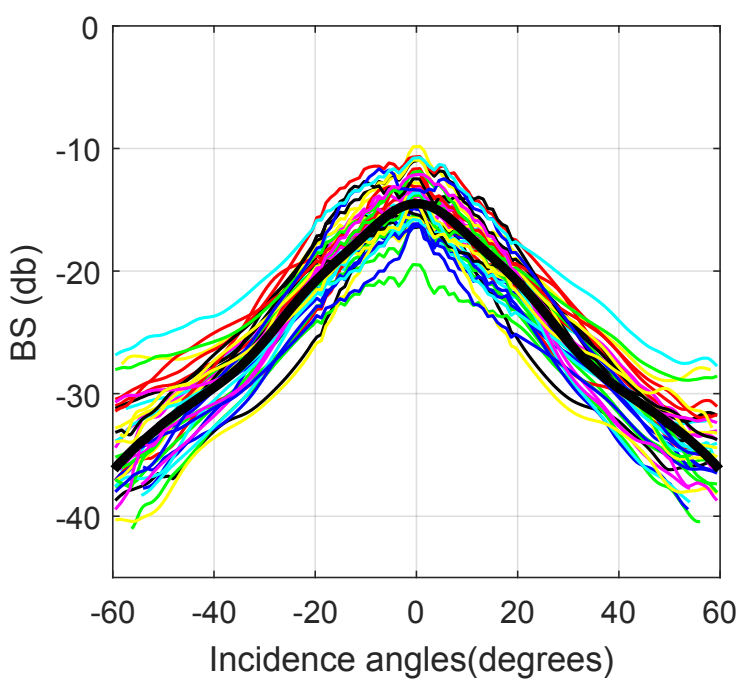

(j)

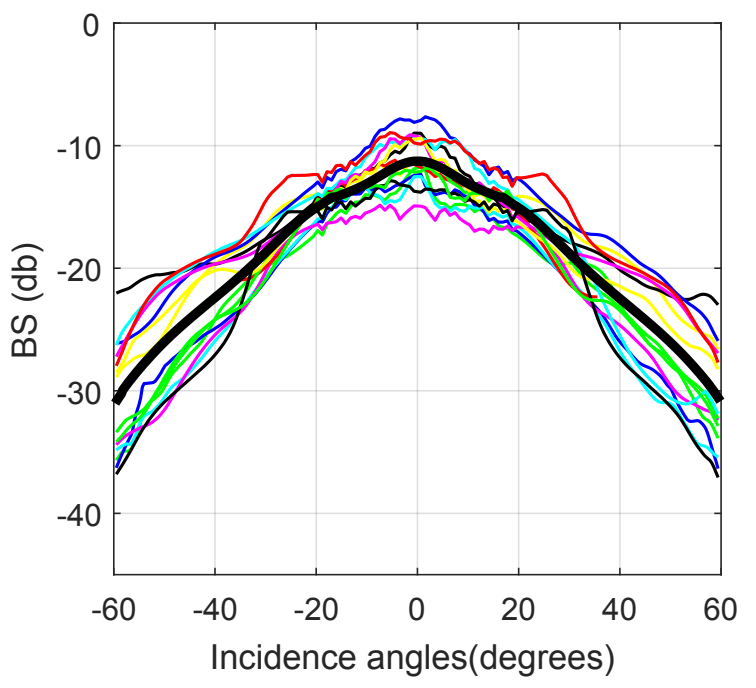

(l)

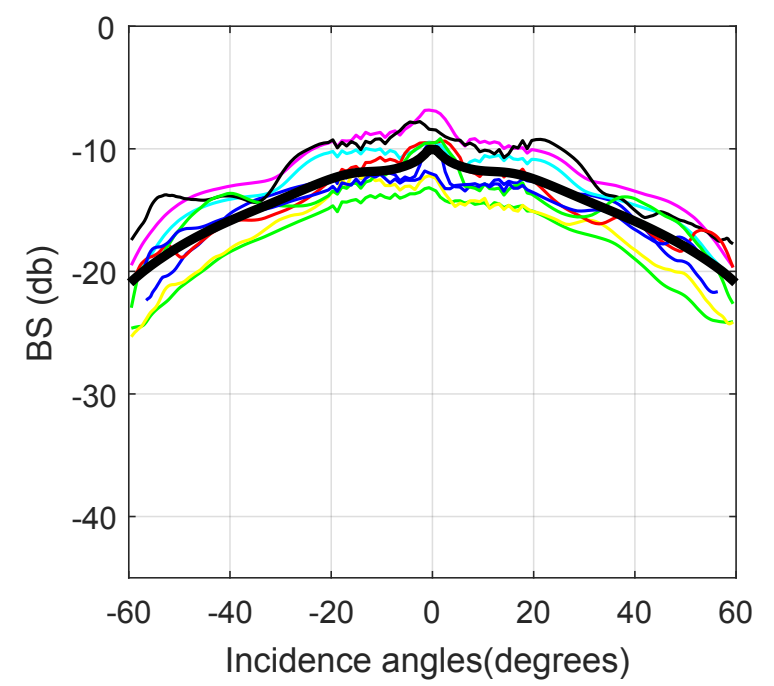

Figure 7: Clustering of extracted curves into 12 sediment types ordered a priori from (a) to (l) from fine sediments to the coarsest ones. Black thick line in each plot corresponds to overall backscatter mean of each class. Figures (d) et (e) correspond to the presence of azimuth dependence of sand backscatter in the specular regime. 


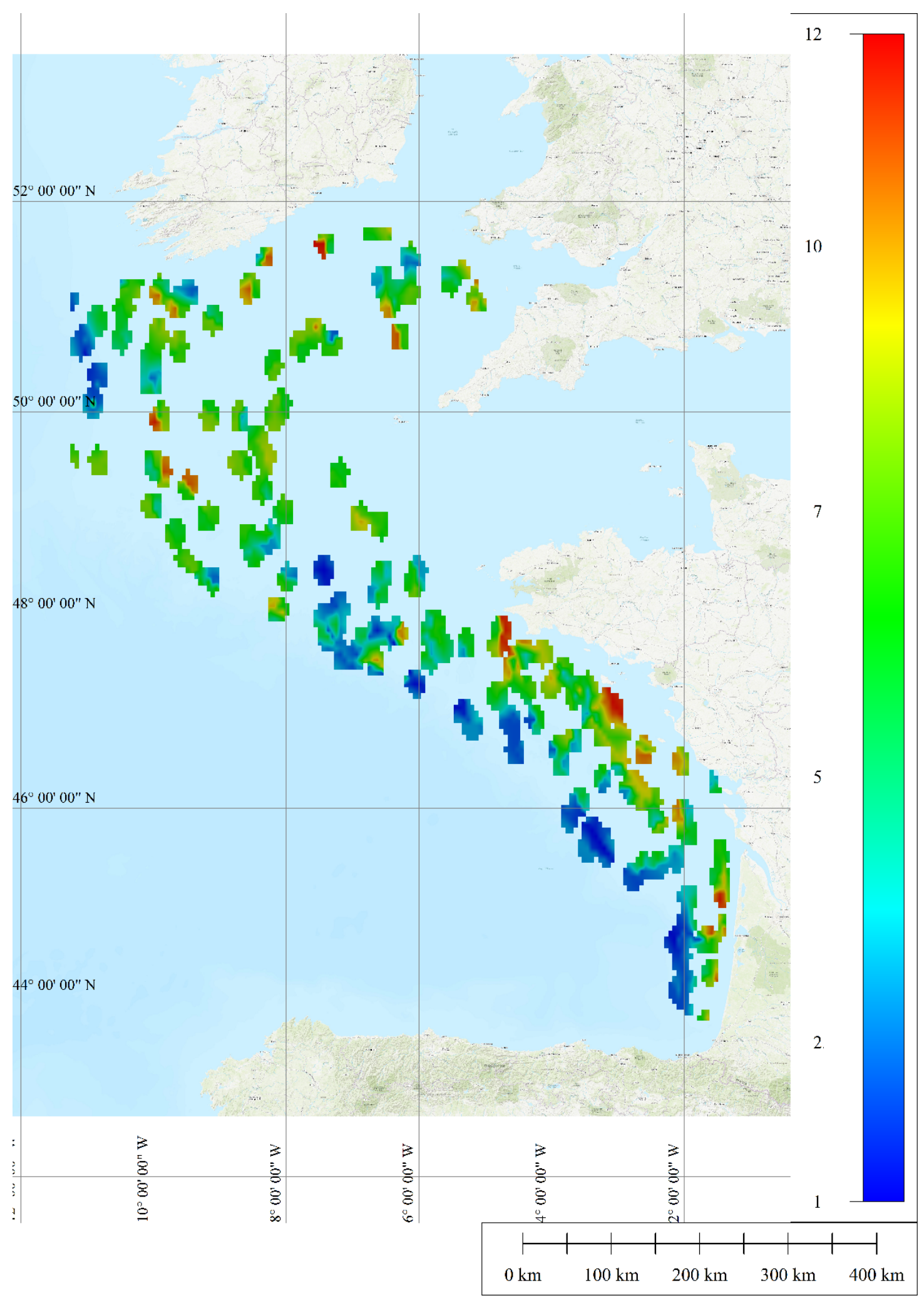

Figure 8: Mapping of 12 acoustic (see Figure 7) classes from a direct clustering of backscatter curves. 


\section{Conclusion}

Shape analysis of calibrated angular response is confirmed as a promising technique for a quantitative automated processing of large datasets of seafloor backscatter. We have successfully applied this technique to a remarkable dataset recorded over several years by one same Simrad ME 70 MBES in the Bay of Biscay and Celtic Sea. The availability of absolute calibrated levels processed with appropriate data reduction was the key to the success of this approach, together with the use of a heuristical model fitting the large variety of angular responses at the scale of an ocean region. In this latest respect, the six parameters ( $A$ to $F$ ) of the Generic Seafloor Acoustic Backscatter (GSAB) considered statistically provide a good clustering of different sediment types and could be a relevant basis for a first library of reflectivity angular response types at the regional ocean scale applicable to monitoring benthic habitats.

The "poor man's segmentation" method proposed here for automatically processing large datasets in the angular space offers potential for the remote discrimination of homogeneous sediments and can be used to improve available broad-scale maps without a great effort, provided that some ground-truth is available. This method provides a fine-scale signal-based segmentation of backscatter into acoustically homogeneous areas similarly to image processing techniques, and exhibiting a great potentiality for seabed characterization. The standard protocol for MBES data collection during the EVHOE sea cruises including a cross-line survey, in addition to bathymetry quality control, allows to rapidly check the azimuth dependence of seafloor backscatter. The backscatter strength dependence with incidence angle, when the MBES is calibrated for absolute level, is demonstrated here to be an efficient tool to detect changes in seabed properties (Figure 6). The first clustering analysis presented above will be very useful for ground-truth collection planned for the future EVOHE sea cruises. The absolute backscatter curves at $90 \mathrm{kHz}$ combined with ground-truth at the scale of the EVOHE area will provide a good database to study the angular backscatter response shape according to grain size and seabed rugosity. Future work will consist in using extracted acoustical parameters jointly with demersal and benthic organisms descriptors to define and map seafloor habitat types in the Bay of Biscay and Celtic Sea. This method can be extended to any hydrographic MBES that can be calibrated, for example using a reference area calibration method; interestingly these sounders provide a wider swath coverage than ME70, and using other frequencies (higher or lower) will give new insights in seafloor characterization. However, time and efforts will be needed to build comparable multi-frequency datasets covering the same extents of these areas.

\section{Acknowledgement}

This project was partially funded by SHOM (Service Hydrographique et Océanographique de la Marine, France) under contract 14CR02. The work was conducted in the framework of the Ifremer RD project $R 403-006$ "Underwater Acoustics". Dr Pascal Laffargue is in charge of the EVHOE data collection with ME70 Thalassa on RV Thalassa; he is gratefully thanked for making available for our study this exceptionally rich dataset. We would like to express our gratitude to Dr Xavier Lurton for his help in writing this paper and many constructive discussions, and Jean-Marie Augustin for his invaluable help for data processing with SonarScope ${ }^{\circledR}$. 


\section{References}

Akaike, H., 1973. Information theory and an extension of the maximum likelihood principle,[w:] proceedings of the 2nd international symposium on information, bn petrow, f. Czaki, Akademiai Kiado, Budapest.

Augustin, J.-M., Lurton, X., 2005. Image amplitude calibration and processing for seafloor mapping sonars. In: Oceans 2005-Europe. Vol. 1. IEEE, pp. 698-701.

Brown, C. J., Blondel, P., 2009. Developments in the application of multibeam sonar backscatter for seafloor habitat mapping. Applied Acoustics 70 (10), 1242-1247.

Brown, C. J., Smith, S. J., Lawton, P., Anderson, J. T., 2011. Benthic habitat mapping: a review of progress towards improved understanding of the spatial ecology of the seafloor using acoustic techniques. Estuarine, Coastal and Shelf Science 92 (3), $502-520$.

CARAIBES ${ }^{\circledR}$, 09/01/2018 v5. Ifremer seafloor mapping software.

URL http://flotte.ifremer.fr/fleet/Presentation-of-the-fleet/Logiciels-embarques/CARAIBES

Cutter, G. R., Berger, L., Demer, D. A., 2010. A comparison of bathymetry mapped with the simrad me70 multibeam echosounder operated in bathymetric and fisheries modes. ICES Journal of Marine Science: Journal du Conseil, fsq012.

Edwards, B. D., Dartnell, P., Chezar, H., 2003. Characterizing benthic substrates of santa monica bay with seafloor photography and multibeam sonar imagery. Marine Environmental Research 56 (1), 47-66.

EMODnet, 09/01/2018 2016. The home of european seabed habitat maps.

URL http://www.emodnet-seabedhabitats.eu/default.aspx?mapInstance=MESHAtlanticMap_\&page=1974\&LAYERS=EUSM2016\& $\mathrm{zoom}=6 \& \mathrm{Y}=44.01531241474476 \& \mathrm{X}=-1.487324218233178$

Fonseca, L., Brown, C., Calder, B., Mayer, L., Rzhanov, Y., 2009. Angular range analysis of acoustic themes from stanton banks ireland: A link between visual interpretation and multibeam echosounder angular signatures. Applied Acoustics 70 (10), 12981304 .

Fonseca, L., Mayer, L., 2007. Remote estimation of surficial seafloor properties through the application angular range analysis to multibeam sonar data. Marine Geophysical Researches 28 (2), 119-126.

Hamilton, L., Parnum, I., 2011. Acoustic seabed segmentation from direct statistical clustering of entire multibeam sonar backscatter curves. Continental Shelf Research 31 (2), 138-148.

Hartigan, J. A., Wong, M. A., 1979. Algorithm as 136: A k-means clustering algorithm. Journal of the Royal Statistical Society. Series C (Applied Statistics) 28 (1), 100-108.

Hasan, R. C., Ierodiaconou, D., Laurenson, L., Schimel, A., 2014. Integrating multibeam backscatter angular response, mosaic and bathymetry data for benthic habitat mapping. Plos one 9 (5), e97339.

Hellequin, L., Boucher, J.-M., Lurton, X., 2003. Processing of high-frequency multibeam echo sounder data for seafloor characterization. IEEE Journal of Oceanic Engineering 28 (1), 78-89.

Hughes Clarke, J., 1994. Toward remote seafloor classification using the angular response of acoustic backscattering: a case study from multiple overlapping gloria data. IEEE Journal of Oceanic Engineering 19 (1), 112-127.

Hughes Clarke, J., Danforth, B., Valentine, P., 1997. Areal seabed classification using backscatter angular response at 95 khz. In: SACLANTCEN Conf on High Frequency Acoustics in Shallow Water. pp. 243-250.

ICES, April 2016. Final report of the working group on fisheries acoustics. science and technology (wgfast). Tech. rep., Vigo. Spain. IHO, February 2008. IHO Standards for Hydrographic Surveys. Vol. Special publication N 44. International Hydrographic Bureau. Jackson, D. R., Winebrenner, D. P., Ishimaru, A., 1986. Application of the composite roughness model to high-frequency bottom backscattering. The Journal of the Acoustical Society of America 79 (5), 1410-1422.

Lamarche, G., Lurton, X., Verdier, A.-L., Augustin, J.-M., 2011. Quantitative characterisation of seafloor substrate and bedforms using advanced processing of multibeam backscatterapplication to cook strait, new zealand. Continental Shelf Research 31 (2), S93-S109.

Lurton, X., 2010. An Introduction to Underwater Acoustics. Principles and Applications, 2nd Edition. Springer-Verlag Berlin Heidelberg.

Lurton, X., Eleftherakis, D., Augustin, J. M., 2017. Analysis of seafloor backscatter strength dependence on the azimuthal angle using multibeam echosounder data. Marine Geophysical Research In Lamarche, G., Lurton, X. (Eds) Seafloor backscatter data from swath mapping echosounders: From technological development to novel applications, 1-21. 
Lurton, X., Lamarche, G., May 2015. Backscatter measurements by seafloor-mapping sonars: guidelines and recommendations. A collective report by members of the GeoHab Backscatter Working Group, 79-106.

URL http://geohab.org/publications/

McGonigle, C., Grabowski, J. H., Brown, C. J., Weber, T. C., Quinn, R., 2011. Detection of deep water benthic macroalgae using image-based classification techniques on multibeam backscatter at cashes ledge, gulf of maine, usa. Estuarine, Coastal and Shelf Science 91 (1), 87-101.

Montereale-Gavazzi, G., Roche, M., Lurton, X., Degrendele, K., Terseleer, N., Van Lancker, V., May 2017. Seafloor change detection using multibeam echosounder backscatter: case study on the belgian part of the north sea. Marine Geophysical Research, in Lamarche, G., and Lurton, X. (Eds) Seafloor backscatter data from swath mapping echosounders: From technological development to novel applications Marine Geophysical Research, 1-19.

URL http://doi.org/10.1007/s11001-017-9323-6

Ona, E., Mazauric, V., Andersen, L. N., 2009. Calibration methods for two scientific multibeam systems. ICES Journal of Marine Science: Journal du Conseil 66 (6), 1326-1334.

Pirtle, J. L., Weber, T. C., Wilson, C. D., Rooper, C. N., 2015. Assessment of trawlable and untrawlable seafloor using multibeamderived metrics. Methods in Oceanography 12, 18-35.

Rousseeuw, P. J., 1987. Silhouettes: a graphical aid to the interpretation and validation of cluster analysis. Journal of computational and applied mathematics 20, 53-65.

Simons, D. G., Snellen, M., 2009. A bayesian approach to seafloor classification using multi-beam echo-sounder backscatter data. Applied Acoustics 70 (10), 1258-1268.

SIS, 2010. SIS, Seafloor Information System, Kongsberg ME70 Operator Manual. Kongsberg Maritime.

SonarScope ${ }^{\circledR}, 09 / 01 / 2018$ v2017. Ifremer acoustic system analysis software. URL http://flotte.ifremer.fr/fleet/Presentation-of-the-fleet/Logiciels-embarques/SonarScope

Trenkel, V. M., Mazauric, V., Berger, L., 2008. The new fisheries multibeam echosounder me70: description and expected contribution to fisheries research. ICES Journal of Marine Science: Journal du Conseil 65 (4), 645-655. 